\title{
GPS and GIS based Soil Fertility Maps and Identification of Soil Related Constraints for Chickpea Growing Soils of Owk Mandal, Kurnool District (A.P), India
}

\author{
D. Salma*, V. Munaswamy, T. Giridhara Krishna, V. Sumathi and B. Ravindra Reddy \\ Department of Soil Science and Agricultural Chemistry, Acharya N.G. Ranga Agricultural \\ University, S.V. Agriculture College, Tirupati-517502, India \\ *Corresponding author
}

\begin{abstract}
A B S T R A C T
\end{abstract}
\section{Ke y w o r ds \\ Owk mandal, GIS, GPS, Soil fertility maps \\ Article Info \\ Accepted: \\ 12 May 2019 \\ Available Online: \\ 10 June 2019}

\begin{abstract}
A detailed soil fertility status of the chickpea growing soils of owk mandal, Kurnool district (A.P) was investigated during 2017-18 to identify the soil related crop production constraints. Geo-referenced composite surface soil samples $(0-15 \mathrm{~cm})$ were collected and analyzed for $\mathrm{pH}, \mathrm{EC}, \mathrm{OC}$ and available $\mathrm{N}, \mathrm{P}, \mathrm{K}$. Almost all soils were moderately alkaline in reaction. The, electrical conductivity (EC) was within safe range for crops $(<0.48$ $\mathrm{dSm}^{-1}$ ). Soil organic carbon varied from 2.7 to $8.0 \mathrm{~g} \mathrm{~kg}^{-1}$ with a mean value of $5.3 \mathrm{~g} \mathrm{~kg}^{-1}$. The mean available soil $\mathrm{N}, \mathrm{P}$, and $\mathrm{K}$ was found to be $121.57,45.43,421.20 \mathrm{~kg} \mathrm{ha}^{-1}$ respectively. Thematic maps were prepared for each soil parameter using ArcGIS package to provide the ready to understand information about soil fertility status and serve as a decision making tool for successful production of chickpea.
\end{abstract}

\section{Introduction}

Chickpea (Cicer arietinum L.) is the largest produced food legume in south Asia and the third largest produced food legume globally, after common bean (Phaseolus vulgaris L.) and field pea (Pisum sativum L.). Chickpea is grown in more than 50 countries $(89.7 \%$ area in Asia, $4.3 \%$ in Africa, $2.6 \%$ in Oceania, $2.9 \%$ in Americas and $0.4 \%$ in Europe). India is the largest chickpea producing country accounting for $64 \%$ of the global chickpea production (1). In India, chickpea accounts for about $45 \%$ of total pulse production.
Similar to the case of other pulses, India is the major chickpea producing country and contribution $75 \%$ of total world chickpea production and grown in 105.61 lakh hectare with production of 112.29 lakh tons and productivity of about $941 \mathrm{~kg} \mathrm{ha}^{-1}$ (2). In Andhra Pradesh, it covers an area of 5.21 lakh hectare with a production of 6.76 lakh tones (3) and contribution is $4.92 \%$ which is far less than the national average which may be due to various constraints. Thus, characterization of spatial variability of soil properties within cultivated fields is essential for site-specific management, also referred to 
as precision agriculture practice. Global Positioning System (GPS) has very wide adaptability in agriculture for generation of thematic maps like land use, land cover, soil fertility maps etc. Determination of spatial soil available nutrient status of an area using GPS helps to formulate site-specific nutrient management. Geographical Information System (GIS) provides valuable support to handle voluminous data, which are generated through conventional and spatial format.

In Kurnool district of Andhra Pradesh, chickpea is in dominant area with other crops like paddy, sorghum, cotton etc. Owk which is one of the mandals of Kurnool district, is considered for the study, located between $15.2167^{\circ} \mathrm{N}$ latitude and $78.1167^{\circ} \mathrm{E}$ longitude. Geographical information system (GIS) is a computer system for capturing, storing, querying and displaying geographical data, Chang (2002) (4). Once the soil fertility thematic maps are created, it is possible to identify the constraints and transform the information about the fertility status of the area. Such maps provide site specific recommendation and validation of soil fertility over the succeeding years.

\section{Materials and Methods}

The Owk mandal of Kurnool district was selected for carrying out the study to prepare GPS and GIS based thematic soil fertility maps and to identify soil related constraints. Location details were recorded by GPS instrument (GARMIN, GPS map 60CSx) for soil sampling $(0-15 \mathrm{~cm})$ of chickpea growing areas. Soil samples collected were brought to the laboratory processed and passed through two $\mathrm{mm}$ sieve for analysis and were stored in cloth bags with proper labeling. All the precautions were followed while processing the soil samples in the laboratory. Soil samples were analyzed for $\mathrm{pH}(1: 2)$, EC (1:2), organic carbon (5), available N (6), available phosphorus (7) and available potassium (5).
Base map of the study area was digitized and geo-referenced. Polygons were superimposed on the geo- referenced map. Latitude, longitude and the point data generated from the soil analysis was entered into attribute table and processed in ArcGIS software to produce thematic soil fertility maps (Fig. 1-7).

\section{Results and Discussion}

\section{Physico-chemical properties}

Soil reaction (pH) and electrical
conductivity

The soil reaction $(\mathrm{pH})$ of the surface soils of different fields of Owk mandal varied significantly from 7.85 to 8.63 with overall mean value of 8.13 (Table 1) and are moderately alkaline in soil reaction. The electrical conductivity of the soils varied significantly from 0.12 to $0.70 \mathrm{dSm}^{-1}$ with overall mean value of 0.26 (Table 1) and remains within safe limit with no salinity hazard. Similar results were reported by Golhar and Chaudhari (2013) (8) at Chalisgaon Tehsil of Jalgaon District, Maharashtra.

\section{Organic carbon}

The organic carbon status of the surface soils of different fields of owk mandal varied significantly from 0.27 to 0.80 per cent with overall mean value of $5.30 \mathrm{~g} \mathrm{~kg}^{-1}$ (Table 1). The soils of Nichanametla village recorded the highest mean value $(0.76 \%)$ of organic carbon, while the soils of sangapatnam village recorded the lowest mean value of $3.4 \mathrm{~g} \mathrm{~kg}^{-1}$. The soils were low to high in organic carbon content. Similar results were also found in Vertisols reported by Awanish et al., (2014) (9).

\section{Available macronutrients}

The available nitrogen content of owk mandal varied from 51 to $203 \mathrm{~kg} \mathrm{ha}^{-1}$ with a mean 
value of $121.57 \mathrm{~kg} \mathrm{ha}^{-1}$ (Table 2). The soils of Singanapalle village recorded the highest mean value for available nitrogen $(155.80 \mathrm{~kg}$ $\mathrm{ha}^{-1}$ ) while the soils of Owk village had the lowest mean value of $88.07 \mathrm{~kg} \mathrm{ha}{ }^{-1}$.The available Phosphorus status of soils of Owk mandal ranged from 17 to $105 \mathrm{~kg} \mathrm{ha}^{-1}$ with a mean value of $45.43 \mathrm{~kg} \mathrm{ha}^{-1}$ (Table 2). The soils of Kondumayunipalli village recorded the highest mean value $\left(82.83 \mathrm{~kg} \mathrm{ha}^{-1}\right)$ for available phosphorus while the soils of Sangapatnam village had the lowest mean value of $24.25 \mathrm{~kg} \mathrm{ha}{ }^{-1}$. The available potassium content of soils significantly varied from 180 to $804 \mathrm{~kg} \mathrm{ha}^{-1}$ with a mean of $421.20 \mathrm{~kg} \mathrm{ha}^{-1}$ (Table 2).

Table.1 Physico-chemical properties of chickpea growing soils of Owk mandal

\begin{tabular}{|c|c|c|c|c|c|c|c|}
\hline \multirow[b]{2}{*}{ S. No } & \multirow[b]{2}{*}{ Name of the village } & \multicolumn{2}{|c|}{ pH } & \multicolumn{2}{|c|}{$E C\left(d S^{-1}\right)$} & \multicolumn{2}{|c|}{ Organic carbon $\left(\mathrm{g} \mathrm{kg}^{-1}\right)$} \\
\hline & & Range & Mean & Range & Mean & Range & Mean \\
\hline 1 & Chennampalli(2) & $8.12-8.58$ & 8.35 & $0.21-0.40$ & 0.31 & $5.10-5.50$ & 5.30 \\
\hline 2 & Singanapalle(3) & $8.16-8.27$ & 8.20 & $0.14-0.21$ & 0.17 & $5.20-5.70$ & 5.43 \\
\hline 3 & Shivavaram(2) & $8.0-8.15$ & 8.08 & $0.12-0.19$ & 0.16 & $3.40-3.80$ & 3.60 \\
\hline 4 & Kunukuntla(2) & $7.90-8.60$ & 8.25 & $0.17-0.43$ & 0.30 & $5.00-7.70$ & 6.35 \\
\hline 5 & Uppalapadu(2) & $7.94-7.98$ & 7.96 & $0.14-0.16$ & 0.15 & $6.40-7.50$ & 6.95 \\
\hline 6 & Junuthala(2) & $7.88-8.01$ & 7.95 & $0.15-0.25$ & 0.20 & $3.60-0.40$ & 3.80 \\
\hline 7 & Kondumayunipalli(2) & $8.04-8.34$ & 8.19 & $0.13-0.31$ & 0.22 & $4.70-0.73$ & 6.00 \\
\hline 8 & Nichanametla(3) & $7.85-8.07$ & 7.96 & $0.31-0.70$ & 0.56 & $7.20-8.00$ & 7.60 \\
\hline 9 & Sangapatnam(3) & $7.86-8.12$ & 7.99 & $0.18-0.37$ & 0.26 & $2.70-3.90$ & 3.43 \\
\hline 10 & Ramapuram(4) & $7.85-8.23$ & 8.07 & $0.21-0.32$ & 0.26 & $3.70-7.30$ & 5.48 \\
\hline \multirow[t]{4}{*}{11} & Owk(3) & $8.30-8.63$ & 8.46 & $0.17-0.20$ & 0.19 & $3.50-5.40$ & 4.43 \\
\hline & Mean & \multicolumn{2}{|c|}{8.13} & \multicolumn{2}{|c|}{0.26} & \multicolumn{2}{|c|}{5.30} \\
\hline & SD & \multicolumn{2}{|c|}{0.22} & \multicolumn{2}{|c|}{0.14} & \multicolumn{2}{|c|}{1.57} \\
\hline & $\mathrm{CV} \%$ & \multicolumn{2}{|c|}{2.74} & \multicolumn{2}{|c|}{55.39} & \multicolumn{2}{|c|}{29.66} \\
\hline
\end{tabular}

Note: Figures in parenthesis indicate the number of samples

Table.2 Available NPK nutrient status in chickpea growing soils of Owk mandal

\begin{tabular}{|c|c|c|c|c|c|c|c|}
\hline \multirow[t]{2}{*}{ S. No } & \multirow{2}{*}{ Name of the village } & \multicolumn{2}{|c|}{$\begin{array}{c}\text { Available Nitrogen } \\
\left(\mathrm{kg} \mathrm{ha}^{-1}\right)\end{array}$} & \multicolumn{2}{|c|}{$\begin{array}{l}\text { Available Phosphorus } \\
\qquad\left(\mathrm{kg} \mathrm{ha}^{-1}\right)\end{array}$} & \multicolumn{2}{|c|}{$\begin{array}{l}\text { Available Potassium } \\
\left(\mathrm{kg} \mathrm{ha}^{-1}\right)\end{array}$} \\
\hline & & Range & Mean & Range & Mean & Range & Mean \\
\hline 1 & Chennampalli(2) & $91-132$ & 111.77 & 26.57 & 41.38 & $477-482$ & 479.23 \\
\hline 2 & Singanapalle(3) & $112-203$ & 155.80 & $69-85$ & 77.75 & $372-515$ & 437.28 \\
\hline 3 & Shivavaram(2) & $122-132$ & 127.01 & $27-36$ & 31.68 & $346-556$ & 450.67 \\
\hline 4 & Kunukuntla(2) & $91-102$ & 96.53 & $63-69$ & 66.15 & $432-804$ & 617.77 \\
\hline 5 & Uppalapadu(2) & $102-142$ & 121.93 & $75-83$ & 78.57 & $300-4333$ & 366.56 \\
\hline 6 & Junuthala(2) & $132-142$ & 137.17 & $24-29$ & 26.18 & $180-207$ & 193.18 \\
\hline 7 & Kondumayunipalli(2) & $112-132$ & 121.93 & $61-105$ & 82.83 & $195-312$ & 253.67 \\
\hline 8 & Nichanametla(3) & $122-152$ & 132.09 & $21-33$ & 27.88 & $344-531$ & 421.96 \\
\hline 9 & Sangapatnam(3) & $51-132$ & 101.61 & $17-36$ & 24.25 & $415-788$ & 663.80 \\
\hline 10 & Ramapuram(4) & $118-152$ & 134.63 & $28-42$ & 29.11 & $190-426$ & 309.33 \\
\hline \multirow[t]{4}{*}{11} & Owk(3) & $61-122$ & 88.07 & $26-31$ & 29.11 & $190-426$ & 309.33 \\
\hline & Mean & \multicolumn{2}{|c|}{121.57} & \multicolumn{2}{|c|}{45.43} & \multicolumn{2}{|c|}{421.20} \\
\hline & SD & \multicolumn{2}{|c|}{29.68} & \multicolumn{2}{|c|}{23.66} & \multicolumn{2}{|c|}{169.42} \\
\hline & $\mathrm{CV} \%$ & \multicolumn{2}{|c|}{24.41} & \multicolumn{2}{|c|}{52.09} & \multicolumn{2}{|c|}{39.52} \\
\hline
\end{tabular}

Note: Figures in parenthesis indicate the number of samples 


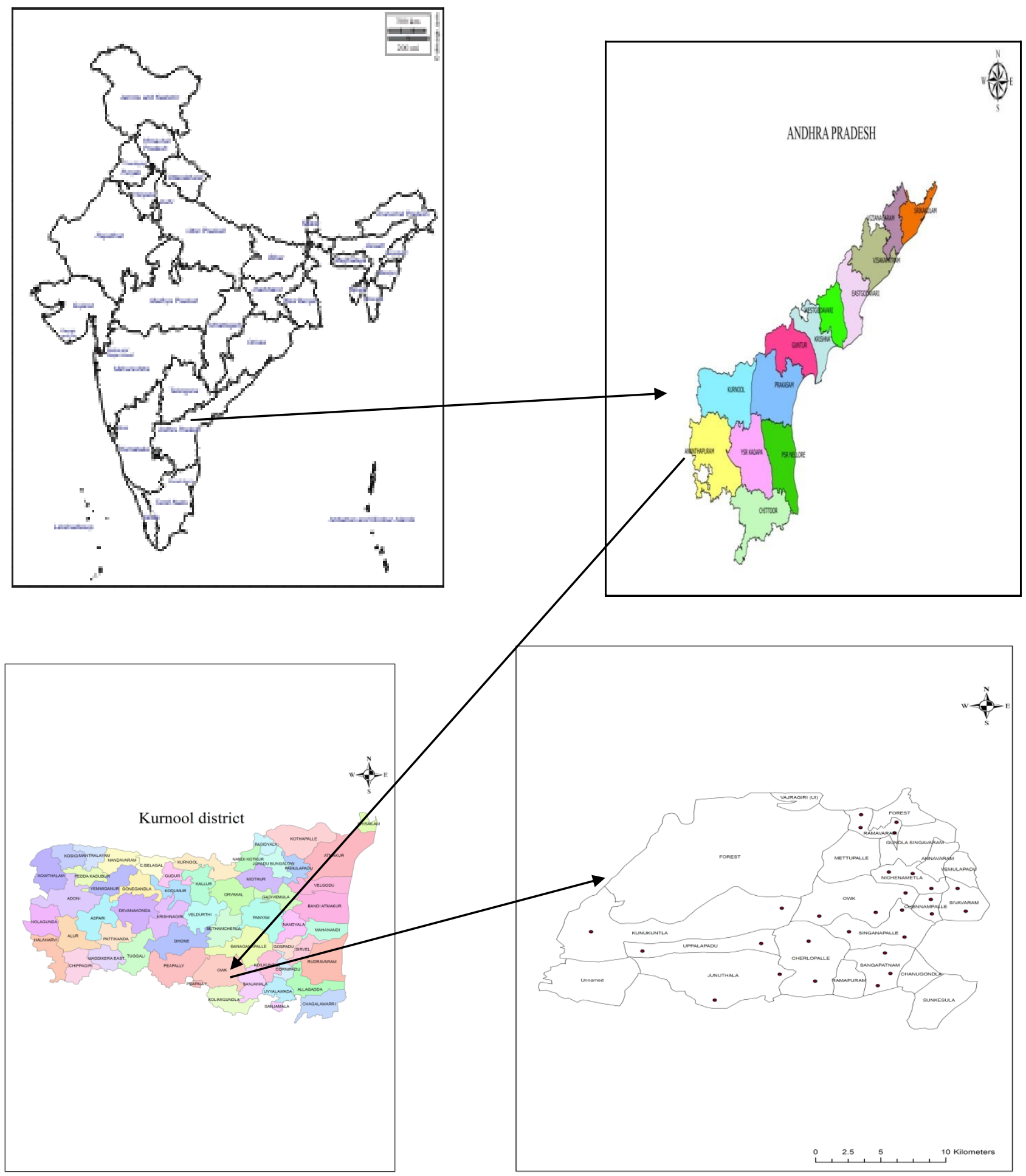

Fig.1. Map of the study area 
Fig.2\&3 Soil pH map of Owk mandal \& Soil EC map of Owk mandal
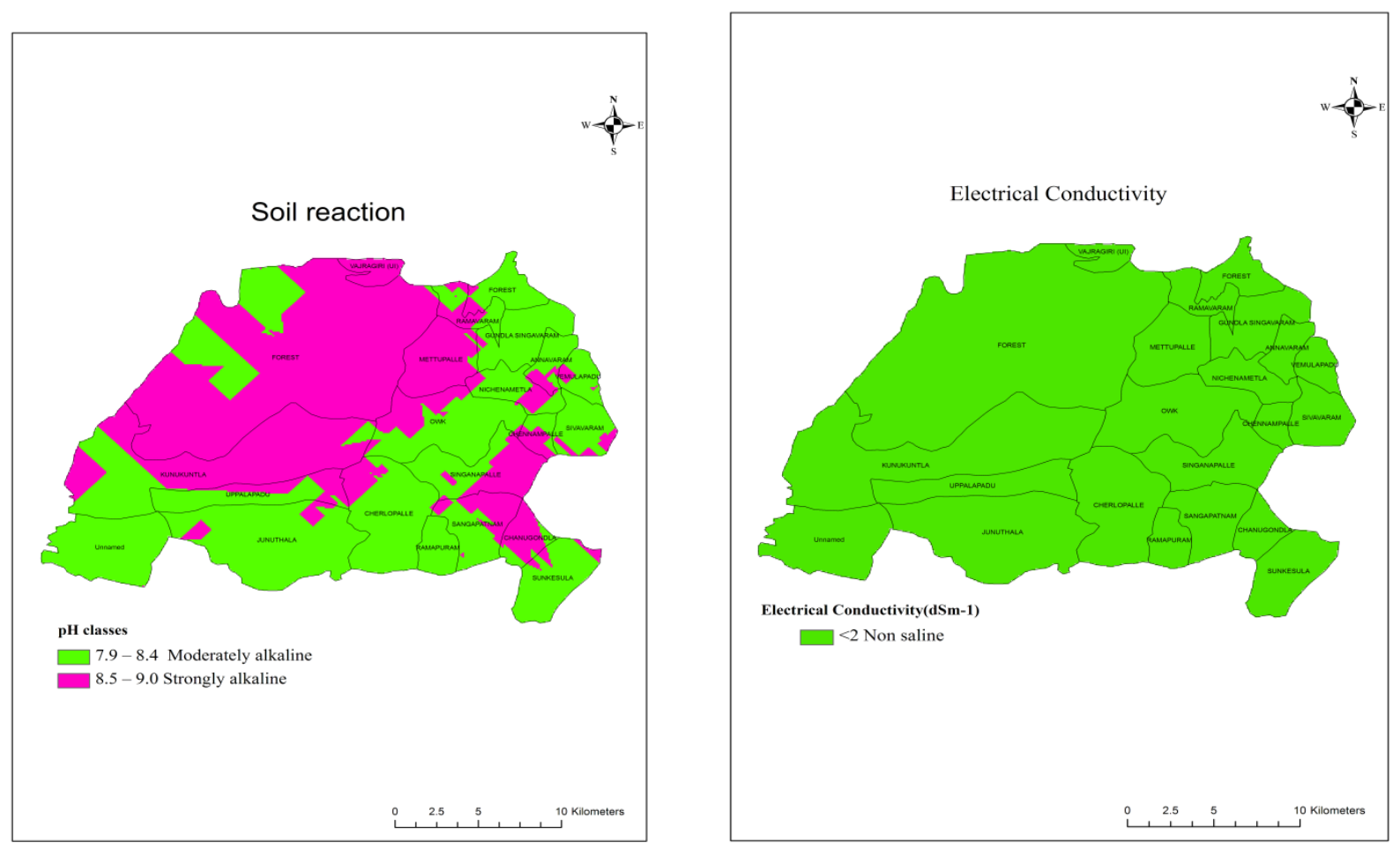

Fig.4\&5 Soil organic carbon map of Owk mandal \& Available Nitrogen map of Owk mandal
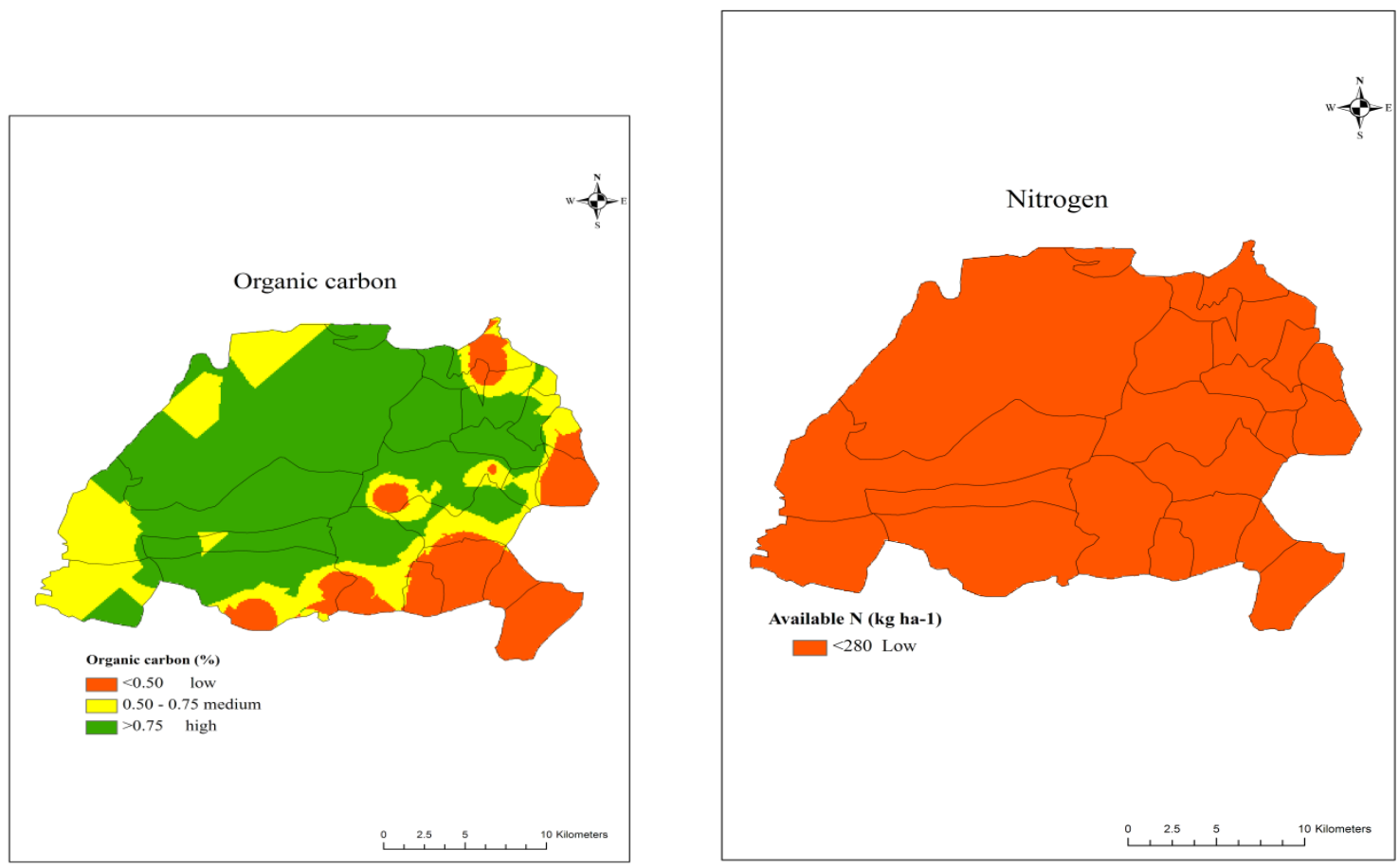
Fig.6\&7 Available phosphorus map of Owk mandal \& Available Potassium map of Owk mandal

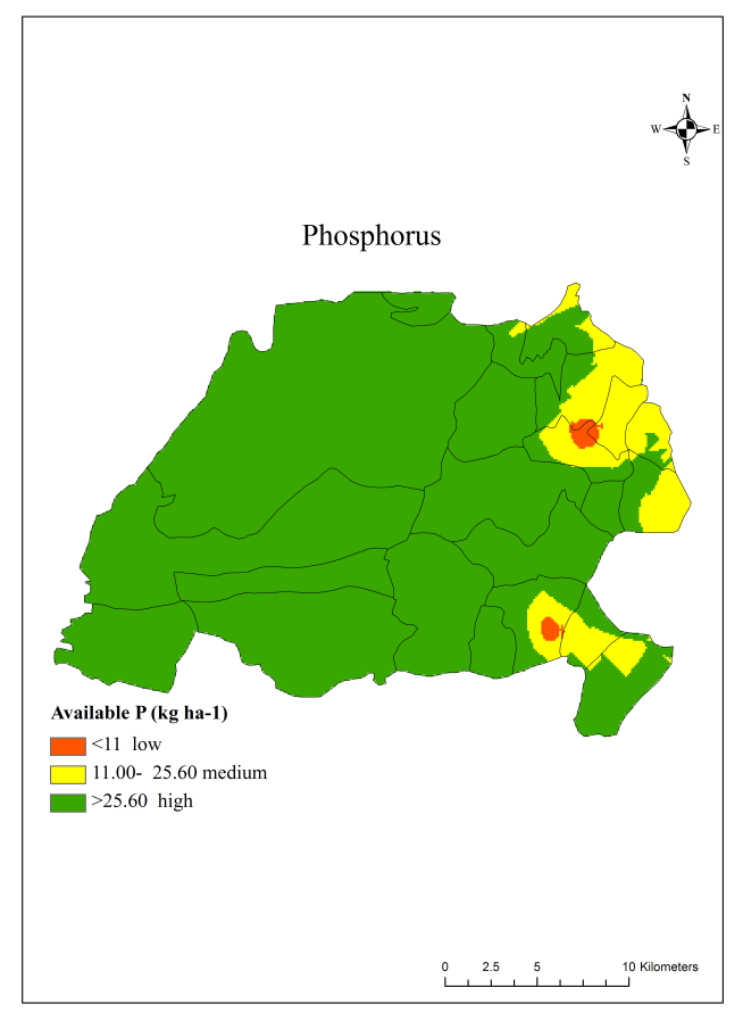

The soils of Sangapatnam recorded the highest for available potassium $(663.80 \mathrm{~kg}$ $\mathrm{ha}^{-1}$ ) while the soils of Junuthala village had the lowest $\left(193.18 \mathrm{~kg} \mathrm{ha}^{-1}\right)$. The soils were categorized as low in available nitrogen, low to high in available phosphorus and medium to high in available potassium. Similar trends of results were recorded by Shinde and Phalke (2013) (10) in the soils of Godavari basin of Beed, Maharashtra.

\section{Recommendations}

A balanced fertilizer recommendation can be made for chickpea crop, based on the available soil nutrient status as observed by the survey and analysis of GPS based soil samples collected from various fields of the study area. Considering status of major nutrients i.e. available nitrogen, phosphorus and potassium; $25 \%$ more than the recommended dose of fertilizer can be applied in the fields where the available soil nutrient

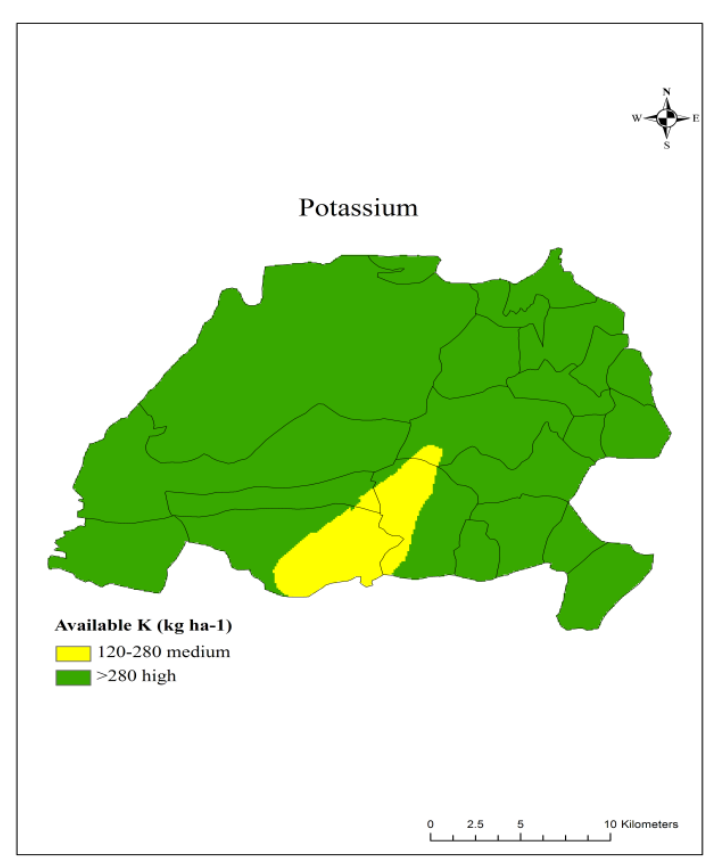

was low. In case of high status of a nutrient, $25 \%$ less than the recommended dose of fertilizer can be given. When the nutrient content of an area lies in medium range, the recommended dose of fertilizer is to be applied (11).

From the study, it can be concluded that, chickpea growing soils of owk mandal are moderately alkaline in soil reaction, nonsaline in nature, low to high in organic carbon content. The soils were categorized as low in available nitrogen, low to high in available phosphorus and medium to high in available potassium. It prioritizes the importance of mapping of different soil fertility parameters over the usual practice of assessing soil fertility on the basis of mean values of the concerned parameters. The use of GPS instrument and GIS package for collection of soil samples and preparation of spatial variable fertility maps of study area will help the local farming community in many ways. It 
will help to monitor soil health from time to time by bringing soil samples from the same spots from which the samples are drawn in the present investigation. By collecting and analyzing the geo-referenced soil samples at designated intervals, the change in soil fertility status can be monitored and remedial measures can also be suggested to maintain soil health for sustainable crop production.

\section{References}

1. Gaur, P. M., Tripathi, S., Gowda, C. L. L., Ranga, G. V., Sharma, H. C., Pande, S. and Sharma, M. 2010. Chickpea Seed Production Manual. Patancheru 502 324, Andhra Pradesh, India: International Crops Research Institute for the Semi-Arid Tropics. 28 pp.

2. Ministry of agriculture and farmers welfare, Govt. of India, 2018

3. DES, Ministry of Agri. \& FW (DAC\&FW), Govt. of India; 2017-18IIIrdAdv. Est.

4. Chang K. Introduction to Geographic Information Systems. Tata Mc-Graw Hill Publishing Co., New Delhi, India, 2002, 348.

5. Jackson, M.L. 1973. Soil Chemical Analysis. Oxford IBH Publishing House, Bombay. 38.

6. Subbiah B.V. and Asija G.L. 1956 Current
Science, 31, 196.

7. Olsen S.R., Sommers L.E.1982. Method of Soil Analysis (A.L. Page et al., , Eds.). Part 2, 2nd Edition, 403-430. Madison, Wisconsin. American Society of Agronomy and Soil Science Society of America.

8. Golhar Nima P, Chaudhari PR.2013. Level of significance of various physical and chemical parameters of soils through Electrical Conductivity, Journal of Chemical, Biological and Physical Science. 3(3): 2051-2057.

9. Awanish Kumar, V. N. Mishra, L. K. Srivastav, and Rakesh Banwasi. 2014. Evaluations of soil Fertility Status of Available Major Nutrients (N, P \& K) and Micro Nutrients ( $\mathrm{Fe}, \mathrm{Mn}, \mathrm{Cu} \& \mathrm{Zn}$ ) in Vertisol of Kabeerdham District of Chhattisgarh, India. International Journal of Interdisciplinary and Multidisciplinary Studies (IJIMS), Vol 1, No.10, 72-79.

10. Shinde LV, Phalke GB.2013. Chemical composition of soil from Godavari basin of Beed (M.S.) India, Bioscience Discovery, 5(1):15-18.

11. Mitra G. N., Sahoo D. and Sahu G.C.1980.Laboratory manual of soil and water testing. Directorate of Agriculture and Food Production, Orissa and Dept. of Soil and Agril. Chemistry, OUAT, Bhubaneswar.

\section{How to cite this article:}

Salma, D., V. Munaswamy, T. Giridhara Krishna, V. Sumathi and Ravindra Reddy, B. 2019. GPS and GIS based Soil Fertility Maps and Identification of Soil Related Constraints for Chickpea Growing Soils of Owk Mandal, Kurnool District (A.P). Int.J.Curr.Microbiol.App.Sci. 8(06): 1241-1247. doi: https://doi.org/10.20546/ijcmas.2019.806.151 